\title{
Dynamic analysis of temporary steel grandstand equipped with different types of bracing system
}

\author{
Natalia Lasowicz ${ }^{1, *}$, and Tomasz Falborski ${ }^{1}$ \\ ${ }^{1}$ Gdańsk University of Technology, Faculty of Civil and Environmental Engineering, \\ ul. Narutowicza 11/12, 80-233 Gdańsk, Poland
}

\begin{abstract}
In the paper, behaviour of a temporary steel grandstand equipped with two different types of bracing system has been analysed through the numerical study. A typical solution concerning application of a diagonal tubular members has been compared with elements proposed by authors and called polymer dampers. A polymer element consists of two L-shape steel members bonded with polymer mass. The aim of the paper is to verify the effectiveness of polymer dampers in reduction of vibrations of temporary metal grandstands subjected to dynamic loads induced by spectators. The results of the study show that the response of structure equipped with two analysed bracing systems is different variable. The application of the polymer dampers results in substantial reduction in structural vibrations. Moreover, the decrease in values of accelerations of the grandstand with polymer dampers allows to maintain comfort of spectators at an acceptable level.
\end{abstract}

\section{Introduction}

Dynamic loads are often considered the most important ones at the design stage of civil engineering structures [1]. Newly designed and erected metal structures are often composed of very slender and light components that are more easily excitable by different types of dynamic load [2]. Wind, earthquake or crowd load effects determine the design procedure of metal structures (that are) regularly subjected to such significant dynamic loads (see, for e.g. [3-8]). Vibrations of civil engineering structures, generated by dynamic loads, may be very dangerous to the structural integrity as well as may act strongly human perception and comfort $[9,10]$.

In the past, metal grandstands were mainly used during sport events. Nowadays, these types of structures are commonly applied for music concerts, festivals or other events with large number of participants [2]. Moreover, the use of lighter and slender structural members leads to the reduction in values of natural frequencies and that is why such structures are more easily induced to vibrations. As a result of this situation, resonance may occur in the case of dynamic loads due to behaviour of spectators (e.g. jumping) which may even cause severe damages to the grandstand [11-14]. Structural vibrations also lead to the

${ }^{*}$ Corresponding author: natmajew@pg.edu.p1 
reduction in comfort of spectators [9,10]. A number of different methods have been proposed in order to minimize such situations. One of the methods is to increase stiffness of the structure [15]. Another solution assumes application of additional dampers so as to increase dissipation of energy during vibrations [16].

In the paper, behaviour of a temporary steel grandstand equipped with two different types of bracing system has been analysed through the numerical study. A typical solution concerning application of a diagonal tubular member has been compared with an element proposed by authors and called polymer damper. It consists of two L-shape steel members L 50x50x5 mm bonded with polymer mass of thickness $5 \mathrm{~mm}$. The applied polymer mass is a specially designed flexible two-component grout based on polyurethane resin $[17,18]$. This kind of material has been already used for filling of cracks in brick walls $[19,20]$. It has been proven, based on the previous experimental studies, that the material is characterized by excellent damping properties [21, 22].

The aim of the paper is to verify the effectiveness of polymer dampers in reduction of vibrations of temporary metal grandstands subjected to dynamic loads induced by spectators. The first stage of the investigation deals with modal analysis so as to determine dynamic parameters, such as modes of free vibrations and the corresponding natural frequencies for both structural models. The second stage of the numerical study concerns dynamic transient analysis. In the analysis, the dynamic load has been assumed a series of synchronous repetitive impacts, as expressed by Fourier series (see [23]).

\section{Numerical analysis}

Two different numerical models of a temporary metal grandstand erected using scaffolding system have been generated using a commercial programme MSC Marc. Total dimensions of the analysed structure are: length $16.8 \mathrm{~m}$, width $10.8 \mathrm{~m}$ and height $7.5 \mathrm{~m}$. The first describes the structure equipped with typical diagonal stiffener members of tubular crosssection, while the second one concerns the structure with polymer dampers. Both models have been presented in Fig.1 and Fig. 2, respectively. Scaffolding system and stiffeners consisting of slender tubular structural members have been modelled by standard two-node beam-column elements, while platforms and benches have been generated as standard fournode shell elements available in the program. In the case of polymer, standard eight-node (six degrees of freedom for each node) solid elements have been used. The base of all models has assumed fixed only in translational directions. Steel, as a structural material, has been described by the following material properties: $E=210 \mathrm{GPa}, \mathrm{v}=0.3, \rho=7850 \mathrm{~kg} / \mathrm{m} 3$. The behaviour of polymer has been simulated with the use of the Mooney-Rivlin material model that is the most frequently adopted method for modelling complex mechanical behaviour of elastomers and rubber-like solids [24, 25]. The following material constants for the five-parameter Mooney-Rivlin model have been applied: $\mathrm{C}_{10}=889.490 \mathrm{kPa}, \mathrm{C}_{01}=-$ $245.840 \mathrm{kPa}, \mathrm{C}_{20}=-155.310 \mathrm{kPa}, \mathrm{C}_{11}=93.786 \mathrm{kPa}, \mathrm{C}_{30}=11.148 \mathrm{kPa}$. The bulk modulus has been set to be $2.5 \mathrm{GPa}$, as commonly used for elastomers and rubber-like materials (see [17, 21]). Structural damping was considered in the analysis. 


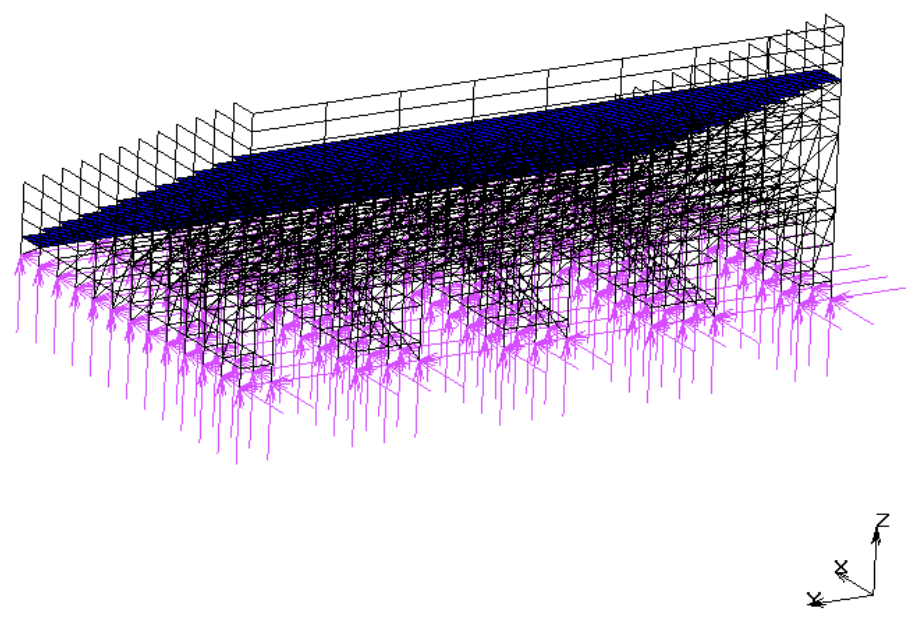

Fig. 1. FE model of temporary grandstand equipped with typical tubular diagonal members.

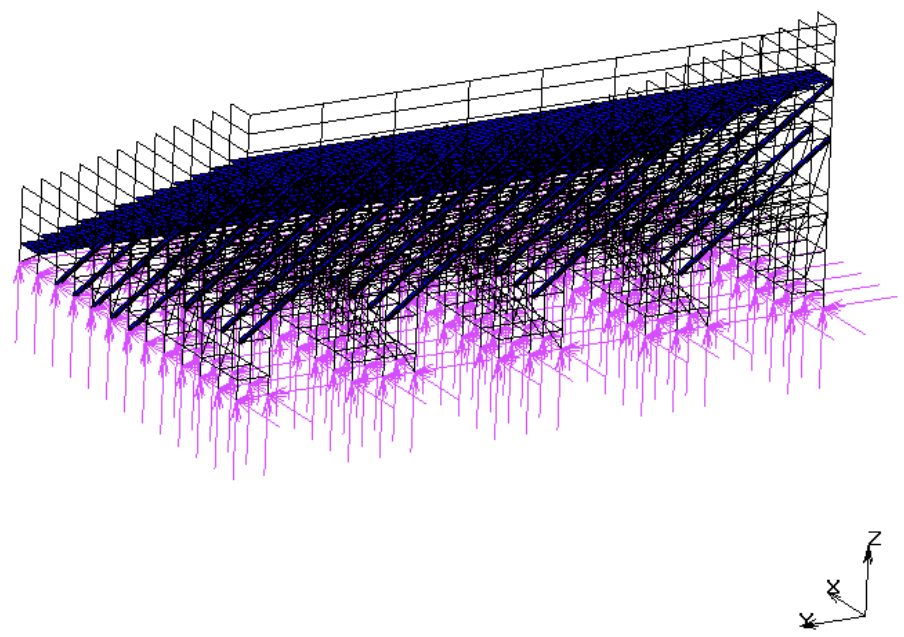

Fig. 2. FE model of temporary grandstand equipped with polymer dampers.

\subsection{Modal analysis}

The first stage of numerical analysis is focused on modal analysis in order to determine horizontal (left-to-right) modes of free vibrations and corresponding natural frequencies of temporary grandstand equipped with two different types of bracing system. In the case of such structures horizontal vibrations are found to be the most important ones $[12,23]$. An empty and occupied structure has been analyzed numerically. In the modal analysis the mass of about 300 spectators has been assumed. First horizontal (Y direction) mode of free vibrations of temporary grandstand equipped with tubular elements and polymer dampers have been presented in Figure 3 and Figure 4, respectively. The values of natural frequencies corresponding to horizontal modes of free vibrations for empty and occupied temporary grandstand are collected in Table 1. 


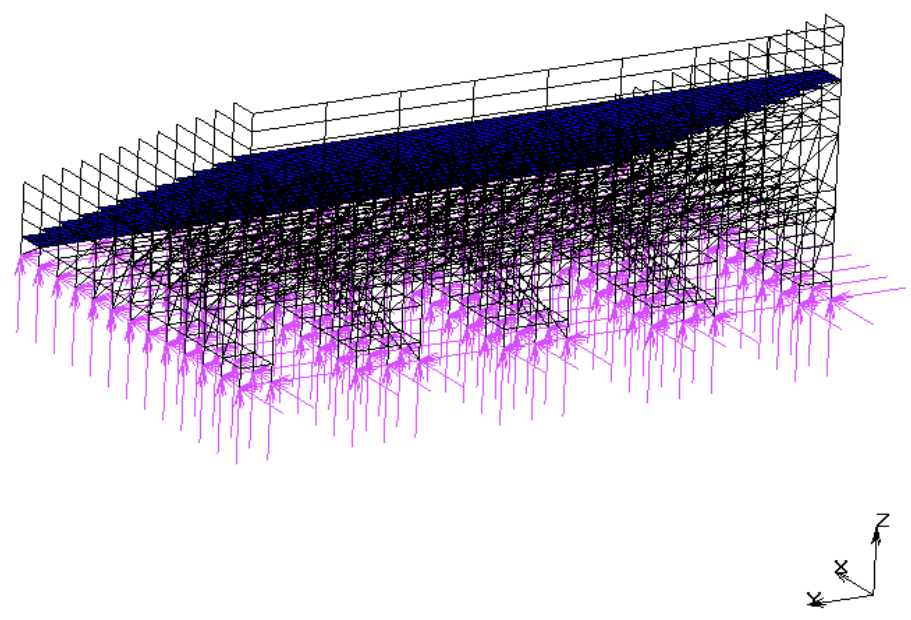

Fig. 3. $1^{\text {st }}$ horizontal mode of free vibrations of temporary grandstand equipped with typical tubular diagonal members (Model 1).

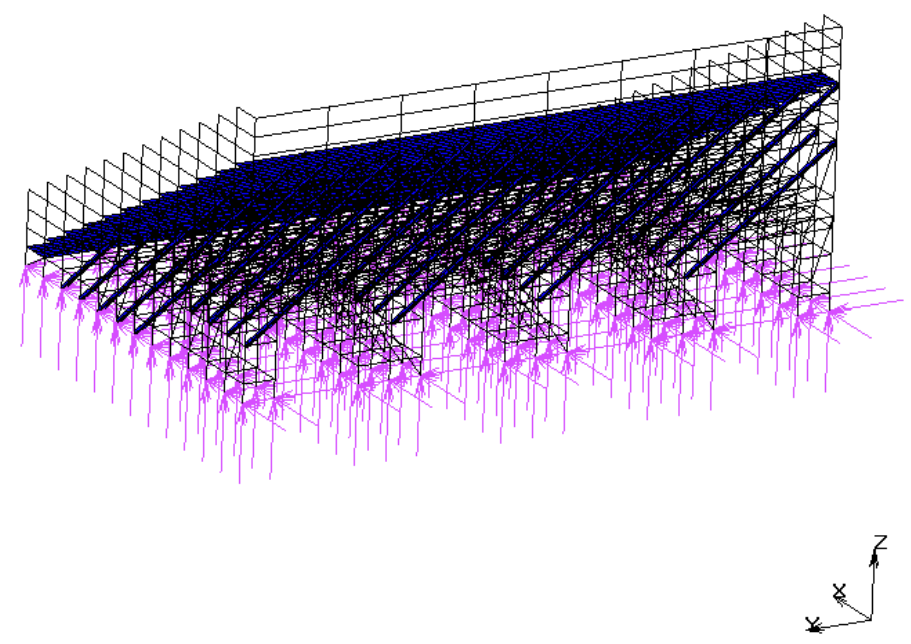

Fig. 4. $1^{\text {st }}$ horizontal mode of free vibrations of temporary grandstand equipped with polymer dampers (Model 2).

Table 1. Natural frequencies determined for an empty and occupied structure equipped with two different types of bracing system.

\begin{tabular}{|c|c|c|}
\hline \multirow{2}{*}{ Model } & \multicolumn{2}{|c|}{ Natural frequency [Hz] } \\
\cline { 2 - 3 } & $\begin{array}{c}\text { Empty } \\
\text { structure }\end{array}$ & $\begin{array}{c}\text { Occupied } \\
\text { structure }\end{array}$ \\
\hline Model 1 & 6.43 & 4.00 \\
\hline Model 2 & 7.00 & 4.55 \\
\hline
\end{tabular}

It can be seen from Table 1 that mass of the spectators significantly decreases values of natural frequencies (by as much as 38\% in the case of Model 1, and 30\% in the case of Model 2). However, there is no significant difference between values of natural frequencies of structure equipped with tubular diagonal elements and polymer dampers. The difference between determined values of natural frequencies are not greater than $8 \%$ and $9 \%$ for an 
empty and occupied structure, respectively. Based on the previous study $[12,26,27]$ it should be underlined that the estimated natural frequency values of an empty and occupied structure are in the safe range.

\subsection{Dynamic transient analysis}

The second stage of the investigation is focused on dynamic transient analysis. The behaviour of temporary metal grandstand equipped with two different bracing systems under human-induced excitation due to jumping has been analysed. In the analysis, the dynamic load has been assumed to be consisted of synchronous repetitive impacts, as expressed by Fourier series (see [23]). According to the Polish Standards [28], additional load in horizontal (left-to-right) direction of ( $6 \%$ of total value of load acting in vertical direction) has been assumed in dynamic transient analysis.

The aim of the dynamic analysis has been conducted to determine peak values of accelerations and displacements of the structure equipped with tubular and polymer elements (compare also [29]). Acceleration time histories for both models obtained at the level of the highest steel platform are presented in Figure 5 and Figure 6. The displacement time histories are presented in Figure 7 and Figure 8, respectively. The peak values of acceleration and displacement of temporary grandstand equipped with two different types of bracing system under human-induced excitation due to jumping at $2 \mathrm{~Hz}$ estimated from dynamic transient analysis are summarized in Table 2 .

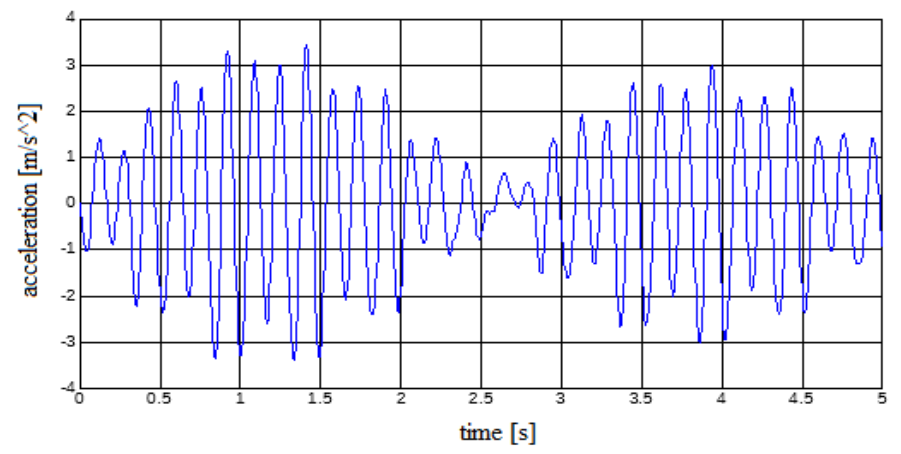

Fig. 5. Acceleration time history for temporary steel grandstand equipped with tubular elements (Y direction).

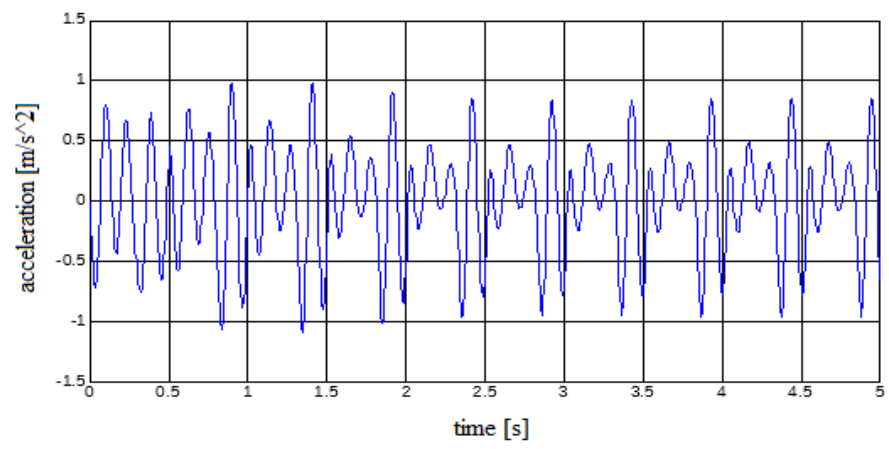

Fig. 6. Acceleration time history for temporary steel grandstand equipped with polymer dampers (Y direction). 


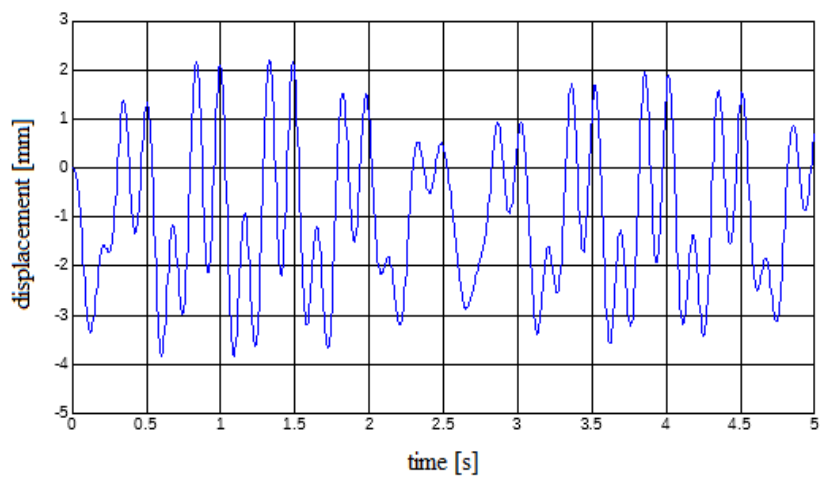

Fig. 7. Displacement time history for temporary steel grandstand equipped with tubular elements (Y direction).

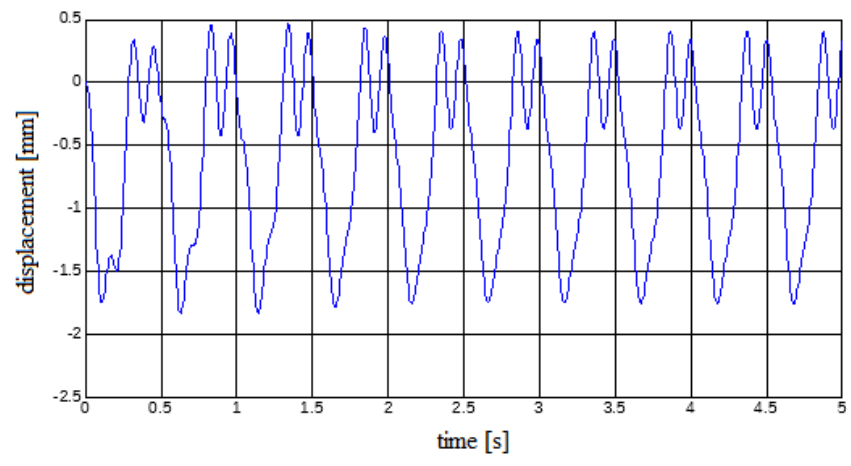

Fig. 8. Displacement time history for temporary steel grandstand equipped with polymer dampers (Y direction).

Table 2. Peak left-to-right horizontal accelerations and displacements for Model 1 and Model 2.

\begin{tabular}{|c|c|c|}
\hline Model & $\begin{array}{c}\text { Acceleration } \\
{\left[\mathbf{m} / \mathbf{s}^{\mathbf{2}}\right]}\end{array}$ & $\begin{array}{c}\text { Displacement } \\
{[\mathbf{m m}]}\end{array}$ \\
\hline Model 1 & 3.42 & 3.83 \\
\hline Model 2 & 1.10 & 1.84 \\
\hline
\end{tabular}

The lowest recommended acceleration value to avoid panic among spectators, is equal to $0.35 \mathrm{~g}$ (where $\mathrm{g}$ is the acceleration of gravity - see [30]). It can be seen from Table 2 that the peak value of acceleration estimated for Model 1 is almost equal to $0.35 \mathrm{~g}$ and it can be considered as unacceptable while the peak value of $0.11 \mathrm{~g}$ has been reached in the case of Model 2 and can be considered disturbing. It should be pointed out that the peak value of acceleration estimated for the structure equipped with polymer dampers is more than three times lower than the value determined for grandstand with typical tubular member. The peak displacement estimated from the dynamic transient analysis for the structure with polymer dampers is more than two times lower than the value obtained for grandstand with typical tubular elements.

\section{Conclusions}

The paper deals with effectiveness of polymer dampers in reduction of temporary steel grandstand vibrations. Typical solution using diagonal tubular elements to improve stiffness 
of such structures has been compared with the application of polymer dampers consisting of two L-shape steel members bonded with polymer mass. In the first stage of the study modal analysis has been conducted in order to determine dynamic parameters, such as modes of free vibrations and corresponding natural frequencies, of temporary steel scaffolding grandstand equipped with two different types of bracing system. Next, dynamic transient analysis has been conducted and behaviour of the structure under human-induced excitation due to jumping has been determined.

The results of the study show that the response of structure equipped with two analysed bracing systems is different. The application of the polymer dampers results in substantial reduction in structural vibrations. Moreover, the decrease in values of accelerations of the grandstand with polymer dampers allows us to maintain comfort of spectators at an acceptable level.

\section{References}

1. A.K. Chopra, Dynamics of Structures (Prentice-Hall, USA, 2010)

2. P. Reynolds, P. Mohanty, A. Pavic, Use of operational modal analysis on empty and occupied stadia structures. Proceedings of 1 st International Operational Modal Analysis Conference, Copenhagen 2005

3. T. Falborski, R. Jankowski, Numerical evaluation of dynamic response of a steel structure model under various seismic excitations, Procedia Engineering, 172, 277-283 (2017)

4. H. Elwardany, A. Seleemah, R. Jankowski, Seismic pounding behavior of multi-story buildings in series considering the effect of infill panels, Engineering Structures, 144, 139-150 (2017)

5. R. Jankowski, S. Mahmoud, Earthquake-Induced Structural Pounding (Springer, Cham, Switzerland, 2015)

6. R. Jankowski, S. Mahmoud, Linking of adjacent three-storey buildings for mitigation of structural pounding during earthquakes, Bulletin of Earthquake Engineering, 14, 3075-3097 (2016)

7. H. Naderpour, R. C. Barros, S.M. Khatami, R. Jankowski, Numerical study on pounding between two adjacent buildings under earthquake excitation, Shock and Vibration, article ID 1504783 (2016)

8. E. Simiu, R. Scanlan, Wind Effects on Structures, Third edition (John Wiley and Sons, USA, 1996)

9. S. P. Nhleko, M. S. Williams, A. Blackeborough, Vibration perception and comfort levels for an audience occupying a grandstand with perceivable motion, Proceedings of IMAC XXVII: A Conference and Exposition on Structural Dynamics, Orlando 2009.

10. N. Lasowicz, R. Jankowski, The effectiveness of polymer damper in damage reduction of temporary steel grandstand, Key Engineering Materials, 713, 171-174 (2016)

11. V. Brito, R. L. Pimentel, Cases of collapse of demountable grandstands, Journal of Performance of Constructed Facilities, 23(3), 151-159 (2009)

12. D. Crick, G. Y. Grondin, Monitoring and analysis of a temporary grandstands, Structural Engineering Report No 275, (2008)

13. N. Jacobs, Temporary Demountable Structures: the need for guidance, The Structural Engineer, 74(5), (1996) 
14. N. Noss, Investigation of human-structure interaction through experimental and analitycal studies (Bucknell University, USA, 2012)

15. T. Ji, B. R. Ellis, Effective bracing system for temporary grandstand, The Structural Engineer, 75(6), 95-100 (1997)

16. N. Noormohammadi, P. Reynolds, Control of human induced vibrations in stadia using a hybrid tuned mass damper, Proceedings of International Conference on Noise and Vibration Engineering, 1119-1132 (2012)

17. T. Falborski, R. Jankowski, Advanced Hysteretic Model of a Prototype Seismic Isolation System Made of Polymeric Bearings, Applied Sciences 8(3), 400 (2018)

18. 18. A. Kwiecień, Polimerowe złącza podatne w konstrukcjach murowych i betonowych (Politechnika Krakowska, Poland, 2012)

19. A. Kwiecień, Flexible polymer adhesives versus stiff mineral and epoxy adhesives tested dynamically on masonry columns strengthened using of bonded GFRP mesh, Proceedings of 8th International Conference on Structural Dynamics, Belgium 2011

20. A. Kwiecień, B. Zając, Energy approach in analysis of masonry columns confined with GFRP mesh bonded on stiff and flexible adhesives, Structural Analysis of Historical Constructions, 1864-1872 (2012)

21. T. Falborski, R. Jankowski, Experimental Study on Effectiveness of a Prototype Seismic Isolation System Made of Polymeric Bearings, Applied Sciences 7(8), 808 (2017)

22. N. Lasowicz, A. Kwiecień, R. Jankowski, Enhancing the seismic resistance of columns using polymer adhesive - experimental study, Key Engineering Materials 624, 478-485 (2015)

23. B. R. Ellis, T. Ji, J. D. Littler, The response of grandstands to dynamic crowd loads, Structures and Buildings, 140(4), 355-365 (2000)

24. R. H. Finney, Finite Element Analysis, Engineering with Rubber: How to design Rubber Components, (Gent A. N., Germany, 2001)

25. R. H. Finney, A. Kumar, Development of material constants for nonlinear finiteelement analysis, Rubber Chemistry and Technology, 61(5), 879-891 (1988)

26. J. D. Littler, Temporary demountable grandstand: dynamic response, Building Research Establishment, 3, (2000)

27. BRE Digest, The response of structures to dynamic crowd loads, 426 (1997)

28. PN-EN 13200-6:2013-02 Obiekty widowiskowe - Część 6: Trybuny demontowalne (tymczasowe)

29. N. Lasowicz, A. Kwiecień, R. Jankowski, Experimental study on the effectiveness of polymer damper in damage reduction of temporary steel grandstand, Journal of Physics: Conference Series, 628, 1-7 (2015)

30. Kasperski M., Actual problems with stand structures due to spectator-induced vibrations, Proceeding of the 3rd European Conference on Structural Dynamics, 455461 (1996) 